\title{
Peace Education as Arts Education: In Search of New Strategies
}

\begin{abstract}
Olga Khyzhna
Doctor of Pedagogical Sciences, Professor, National Pedagogical Dragomanov University (Kyiv, Ukraine)

E-mail: khyzhna@gmail.com

ORCID: 0000-0002-8740-2533

Antonina Lendiel-Siarkevych

Ph.D., Senior Lecturer, Mukachevo State University (Mukachevo, Ukraine)

E-mail: tlendel@bigmir.net

ORCID: 0000-0002-4735-1743

The problem of peace education is in the sharp demand in the modern world. The art in general, and music in particular, have significant impact on a person and the content of his usual activities. Music, as a logical and expressive construction and a psychological phenomenon, contains possibilities for harmonization of personal, social and planetary life. Temporality of music, its actualization of the present, orientation to the eternal meanings and values, archetypeness and plasticity of the content and the ways of its perception, form the basis for understanding music as a universal communication mediator and an important factor in stabilization of contradictions and conflicts. The study demonstrates the potential of arts education to act as one of the instruments of peacebuilding at the present stage of human development.
\end{abstract}

Keywords: peace education, peacebuilding, arts education, music, temporality, duration, harmony

Received: January 25, 2018; accepted: March 10, 2018

Philosophy and Cosmology, Volume 21, 2018: 74-83

DOI: $10.29202 /$ phil-cosm/21/8

\section{Introduction}

Analytical discourse of the present, as a rule, is presented in negative and depressed tones. In the history of the Western culture, the disadvantages of socio-cultural and political life were explained by the lack of education and upbringing. Modernity produces such challenges to humanity, which in a new way actualize the problem of peaceful coexistence on the planet. Hot military confrontation, clashes in the information and virtual space, post-colonialism and

(C) Khyzhna, Olga, 2018

(C) Lendiel-Siarkevych, Antonina, 2018 
decolonization practices, alienation of personality and globalization tendencies - all these pressing issues require the development of new effective education strategies that focus on peace, sustainable development and the harmony of opposing trends and directions.

In personal terms the issue of peace and education, as a way of its obtaining, is no less urgent and in demand. The consciousness of a modern man is fragmented and chaotic, which is the result of a massive informational attack on the part of the social culture. Therefore, the question of harmonization of the contradictory tendencies in a single concept of peace is an urgent issue of modern education in the world as a whole, and in Ukraine in particular. The practices of decolonization and the principles of post-colonialism require well-balanced implementation, especially in the higher education system as a leading element of intellectual and spiritual activity. Accordingly, the general concept of a security strategy and its realization in a certain context also appears as an important problem of the educational work, "The theory of war and peace reveals the ways of the means by which it is possible to maintain a regulatory compromise in a mental space. Mainly, the ways and means are concentrated in educational technologies, the impact of which is precisely directed to the formation and maintenance of certain stereotypes and sets in a rhizome of mental space" [Bazaluk \& Svyrydenko, 2017: 95]. Therefore, the education of peace should be a leading area of the educational management and educational diplomacy, which is convincingly grounded by a number of Ukrainian researchers: "Educational diplomacy uses diplomatic tools productively to mitigate the contradictions that exist in different sectors of education, between different stakeholders in order to overcome challenges and implement transformational education strategies with success" [Kyvliuk et al., 2018: 133].

Taking into account such an important issue of research, that is actualized by the geopolitical confrontation in the territory of modern Ukraine, and also on the basis of the generally recognized need to promote peace building through education, the involvement of all effective transformation tools is appropriate and justified. One of the most effective in the field of practical training of peace is the phenomenon of music. The justification of the relevant strategy and its implementation by means of musical creativity is the main content and purpose of the article.

Consequently, in the philosophical studies of the phenomenon of music two main lines are distinguished: ontological (Pythagorean-Platonic) and psychological (Aristotelian). Let us consider the content of each of them considering a paradigm of arts education as an instrument of peacebuilding more substantially.

\section{Music as the construction of the universe: an ontological dimension}

The Pythagorean-Platonic concept of the phenomenon of music produces an idea of the coherence and interrelation of all things of the world, the Universe and Man through music as a theoretical and cognitive structure. The rhythm of music is, in its essence, the dynamics of the Universe itself, and its duration and content are the logic of life itself. Note that modernity reduces and refutes largely the archaic myths. Therefore, antique enlightenment, profound on content and accuracy, acquires new modifications in the process of formation of science as a way of cognition and social institute. The problem of personality and the inner spiritual world of man, as a result of spread of the Christian ideological paradigm, the problem of objectification and social and political assimilation in the speculative systems of the German classics, the role of genius and freedom in romanticism make their own adjustments to the methodology of interpreting music as a reflection of the Universe. 
The non-classical paradigm of thinking, philosophy and science deviates from the category of substantiality and focuses on the procedurality and regularity of the formation of the world phenomena. Therefore, the understanding of the world, being and essence of man, his life strategies form a different methodology of explication of content and become "compatible with music as a phenomenon and heuristic model. The categorical discourse of being as procedurality, duration and fluidity in a personal and universal dimension is worked out by the author of the fundamental ontology Martin Heidegger. The metaphysical problems of the whole and part, actual and potential, essence and representation find the adequate embodiment and illustrations in the philosophical analytics of a phenomenon of music. So, Oleg Bazaluk, examining the thesaurus of Heidegger's analysis, observes, "True Heideggerian enlightenment 'Dasein' cannot be shown clearly in the available forms, as any transformation of the process into existing forms leads to its fragmentation, and fragmentation is no longer a process. It is a set of separate fragments, the importance of which depreciates rapidly in time, because pulled out from the process, they do not come down to the process any more" [Bazaluk, 2016: 32]. That is, the semantic units recorded in concepts, schemes, and typologies represent the meaning of a phenomenon that has an ontological-temporal dimension. Rational knowledge is carried out as a post factum concerning the rapid development of the existence of the world. Music, by contrast, is relevant in its procedurality, the dialectics of the whole and part is organic for the nature of musical phenomena. Therefore, in the ontological aspect, music is an illustration of Haydegger's analytics of 'Dasein'. Indeed, Genesis (being), if one refuses to understand it as a universal predicate, manifests itself in the horizon of Time, or temporality of content-determined existence.

So, music, as a phenomenon, is accumulated in the duration of substantial sounding. If rational constructions describe the events that have already taken place, then music is modern in the relevance of its existence. In addition, there are no sense and value of music in the fixed form of music paper, but in the temporality of actual implementation. And if the rational and logical concepts are doomed to substantiate their own authenticity in the adequacy of reality, then music is the method of 'gathering', experience and comprehension of the world, and, therefore, it is self-valuable in the epistemological terms. In view of the implementation of predictive strategies, music is also a productive phenomenon. The logic of the composition is not accidental, but natural and determined (both by the author and the essence of Life/being), "The philosophy of cosmos exerts itself the existential essence not only in here-and-now-being-in-complication, but also implies (asks) in the future - hereand-there-being-in-complication" [Bazaluk, 2016: 38]. Consequently, music is temporality that actualizes memory in the present as in the past and the future as a project, anticipation. That is, it implements different timing modalities, different configurations of content and presentations in actuality.

It should be noted that in the analytics of 'Dasein' Heidegger appeals to the literature, namely to the artistic poetic word as a metaphorical expression of the complexity of Genesis/ being/life. Language, as a semiotic system, is plastic in its form and large-scale according to contents tools for implementation of reflexive practices. But at the same time, it is peculiar to language, as a universal semiotic mediator, on the one hand, formalization as a technology of objectification, and on the other hand, polysemanticism of speech means. In principle, music does not require such verification, the effectiveness of its influence is indisputable at the pre-linguistic, archetypal level of the human psyche/ mentality. Music activates the empathic mechanisms of attraction and communication just because of psycho-emotional factors of influence. 


\section{Music as Emotion: Psychological Dimension}

The Aristotelian tradition of interpreting music through attribution to the psyche and soul of a person, as well as its cathartic potential, draws the attention of researchers and educators well grounded. The reasonable question arises: why does the influence of music change the worldview, feelings and aspirations in humans? What intentions of a musical organization motivate a person to a certain emotional order and determine the content of daily practices and the model of self-identification: from the ethnic and political to the personal sphere. Art in general and music in particular, have the ability to transform the power of emotions, affective energy into the relevant activity. In addition, the task of upbringing is precisely in achieving a positive effect in productive activity, in reconciling man with himself, society and the whole Universe. Music does not 'tame' the affects by the force of political coercion, or the morality of public opinion, but by means of an example of expediency and integrity of harmony.

Indeed, the prerequisites for the transformation of individual ordinary experience into a universal mechanism of attitude and world outlook undoubtedly include an aesthetic factor. The combination of contradictions of reality into a single motivational and activity strategy of the individual cannot be realized only on the basis of rational thinking. Emotions, aspirations and preferences of a person determine one or another choice, the course of any activity. In addition, music, as an important factor in influencing on the emotional sphere, is an important tool of the educational work. This is due to the special plasticity of perception of the musical form, which is isomorphic in relation to human feelings. Indeed, music does not require translation or ethno-cultural adaptation. The logic of the musical form is acceptable and understandable for different countries, age groups and socio-professional belongings. In addition, the universality and openness of the musical form is an effective source of communication and adaptation, it demonstrates perfectly a wide range of emotional experiences, which affects positively the development of emotional intelligence. Moreover, as it is known, emotional intelligence is not just a necessary condition for successful communication, but it is also defined as one of the basic principles of the world and Ukrainian education. Therefore, music as an element of educational work, and the peace education in particular, is not only a communicative and heuristic element, but it is also a method of harmonizing the psycho-emotional component of a person.

Let us note that the problem of the relationship between the utilitarian pleasure and rational-logical understanding of the aesthetic phenomena in general, and the musical form in particular, has a long history of research and analysis. At the same time, we should note that aesthetic pleasure is an incentive and motivator for finding an appropriate interpretative practice. Therefore, music determines the relevant intellectual work, without which reflection is impossible, and, accordingly, the implementation of the strategy of peace and stability. Desire for peace and stability, expediency and balance, all this is the attributive essence of man. Only a crazy being does evil for the sake of evil. Any aggressive or deviant behavior is caused by a sense of injustice and inconsistency with the ideal of stability, peace and harmony. Realization of human life is motivated by considerations of expediency and integrity, harmonization of the personal being with universal one. Therefore, the aesthetic with its non-utilitarian pleasure of perception and attitude plays a significant role in reconciling the conflict of interests, harmonization of contradictory strategies of an individual and society. And there is the most important thing: it reveals a wider range of opportunities for selfidentification and self-realization, which are able to level potential conflict situations. 
Why does that happen? What in the nature of music harmonizes the human essence and produces a positive potential of activity? Music is the being of the actual present that translates memory, as a historical and cultural experience into the future, as a design of the ideal, a project. The peculiar temporality inherent in music forms the existential experience of a reflexive reality. Namely, it 'collects' to the integrity the essential projections of a person, realizing at the subconscious level the adoption of vital decisions and evaluations.

The combination in music of the fluidity of the work and the constancy of spiritual content, the completeness of the composition and the multi-vector of its interpretation and explication speak about significant projective possibilities in terms of updating, forming and directing emotions in the corresponding stratagem of life and practice. The perception and experience of the musical work allows a person to stop the rapid flow of everyday life, which is difficult to be reflected. The special temporality, which creates the sound of music or the projected semantic continuum, sets qualitatively different vibrations for the human soul. A sense of the fluidity of time against the background of the constant universals of the world - all this makes man look at the ordinary things in his life in a different way. The trajectory of self-identification extends from the immediate range of daily practices to the general context of the universe's eternity. From this perspective, perceptions of causes for everyday conflicts lose their importance and significance. Consequently, the educational potential of music, its strength "lies in the fact that there is a special simulation of emotions in it" [Bahtizina, 2012: 81].

Music has an attribution of being exclusively in time. Time is decisive in relation to the essence of human existence. The Bergson's category of 'duration' (durée) reveals a specific human way of feeling and experiencing of time. Obviousness of such extent of time coupled with the semantic content is music. It has been known for a long time, that self-identification of a person due to the prevalence of a separate time mode is disastrous. Thus, concentration on the past threatens with manifestations of the ressentiment and revanchism that finally bring to menacing of ideological beliefs. Focusing on the future, as the most valuable and significant field of investment in the subject's activity, causes increased anxiety and related neurotic disorders. Music, through aesthetic pleasure and intellectual suggestion, harmonizes the horizon of human being in the time dimension. The dynamics and dialectics of the mutual transition of the discontinuity and chaos of human existence to a conscious order and organization are reflected just in the construction of a musical work. Therefore, the perception of musical works helps a person find balance in his life and his own aspirations and beliefs.

The emotional state created as a result of listening to musical works integrates the fragmented human psyche into the assembled integrity necessary for a full-fledged life and peaceful coexistence. Such effect is based on the organic unity of the information component of the musical composition with its value verification and emotional tension. There are all bases to consider this influence as spirituality of personal formation and development. Based on the anthropomorphic nature of music, we should note that musical influence is carried out on spirituality of the personality integrating the chaos of objectification and alienation. Among others, it is just the intonation inherent in the melody that implements such effect of influence. Educational potential of music is articulated in transferring a rich palette of human emotions, expanding borders of perception and understanding of emotional intelligence, revealing variations of life experience on a pre-linguistic, but reflexive level: "Music can teach a person to feel and understand his own feelings. It has no equal in the art of formation of a human soul" [Bahtizina, 2012: 123]. The fact is that music is plastic in formal content and holistic in terms of spiritual meaning. Therefore, it causes systemic influence on human 
consciousness and feeling, transforming both the individual and the way in which it interacts with the world.

However, understanding music as emotion does not mean its illogical character. The archetype of the mental structures laid down in music is a reflection of the nature of human thought. After all, emotions and thinking are not contradictory concepts, but mutually supplementing ones. Music should be understood as an emotionally loaded, prolonged and harmonized process of human thinking. 'Living' the aesthetic experience of a musical composition changes the focus of perception and assessment of reality. Music reduces the routine of everyday life and teaches us to think in the categories of eternity. Therefore, music performs the function of human reconciliation in all vectors of his self-realization. In addition, the most important fact, music is transcendental in its essence. Its sense and mission consists in harmonization of human life through a prism of eternity, imperishability of ideals and values. That is why music is an important tool for transforming the desired one into possibility, and possibility into reality. Transformation of the desirable in possible, and possible in valid. The whole process of education is such transformation, and only music makes this process expedient aesthetically and pleasant emotionally. The peace teaching by means of music appeals to the ancient principle of paideia as the basis of inculturation and socialization: "The general philosophical context of determination of the principle of paideia is based on understanding of it as an ontological process, the purpose of which is the total transformation of the human nature as the formation of a personality, self-consciousness and public consciousness" [Yatsenko, 2017: 82]. Based on the mentioned above, we should note that the educational possibilities of music are used very little, and the potential of musical education is underestimated.

\section{Music as Harmony: Impact Factor in Peace Education}

The statement looks logical that the peace-building potential of educational influence can be studied fruitfully using the concept 'harmony'. We consider it is expedient to dedicate a few sentences to the essence of the concept of noosphere humanism, popular in the postSoviet area, as an educational strategy. The logic of noospheric humanism, which allows a person to find a fairly rational common language, the common sense of history, general world outlook, can serve as an important catalytic factor for the transition from the general consumer mentality to the psychology of planetary constructive creativity. This awareness includes or should include understanding of the direction of the next global development to achieve the highest viability of everyone, not just the chosen ones, and, consequently, the development of planetary projects that will contribute to such direction of development.

Man is polyfunctional by one's nature. One's internal world is full of polyphony of interconnections. And the system of artistic education, in our opinion, must comply with this important principle of organization of the human personality. Modernization of the system of higher education, integrating into the noosphere, ontological paradigm of ecological consciousness, personality-oriented and evolutionary-synergetic paradigms, reflects, accordingly, its noosphere, ecologically oriented, humanistic and physical component. At the same time, it operates with the acquired theoretical and methodological, and methodological tools.

Humanization of higher education at the present stage is understood by us as a being produced phenomenon within the framework of science and society, ethical teachings and the totality of humanistic knowledge, ideals of the future social structure based on the idea of social and natural consent. Noosphere thinking establishes and implements cognitive relationships 
of logical, predictive and practical orientation. The system of moral principles, beliefs, and programs of social life is aimed at harmonizing relations in the system of 'man-societynature'. Practical skills, abilities in the conditions of understanding and solving noosphere and humanistic problems, the 'behavioral' projection of the ideological culture, reflecting the degree of internalization of the noohumanistic knowledge, values, ideas, thinking, feelings of the individual in everyday behavioral status, manifests itself in psychological, theoretical and practical readiness to carry out transformative activity according to the laws of beauty and harmony.

These are the basic principles of cultivating peace and harmony in the traditions of postSoviet education. Western theorists of peace education offer other initial positions in their theoretical models of education and the analysis of peace. Proceeding from the reasons that music is a fundamental step of reflexive activity, or in other words, it has archetypic structure and attribution, then its involvement in the education of good is important and necessary. However, the problem of peace is just as long as the world itself. In particular, Jeff Lewsader and Judit Myers-Walls point out: "Peace education has probably existed informally ever since humans recognized violence and its alternatives" [Lewsader \& Myers-Walls, 2016: 34]. And for solving this important problem, specialists involve a variety of methods and techniques. However, not every factor of environmental impact has the ability to become a peculiar point of bifurcation, which disturbs the balance of an unstable system. But a significant amount of output data makes it impossible to validate the analytical procedure. From the chaotic flow of the phenomenal sphere, consciousness chooses selectively the most essential ones for itself. What causes this choice? Conducted empirical studies prove the following: "As we identified children's developmental levels of peace understanding, we felt it was important to consider the cultural activities and contexts - everyday occurrences in which individuals within the community participate (e.g. through daily household routines, school, and work) - in predicting and accounting for children's understanding" [Lewsader \& Myers-Walls, 2016: 3]. So, to isolate, or stratify the determinants in the educational process, the task is rather illusory. However, music is not just a fragment of the context, it is able to change the context, fill it with other semantic and emotional content.

Peace as a concept and as a goal of educational work is a universal phenomenon, as well as a phenomenon of music. This characteristic proximity does not merely combine these concepts into a single field of practical implementation, but it sets a special vector of social and cultural, and political orientation. As rightly pointed out by Hella Behr and others, "We observe that there is no national or mono-cultural perspective on the content of peace education, but a curriculum for peace education is constituted by practical experiences and philosophical teachings on non-violence from a global, cosmopolitan perspective" [Behr et al., 2018: 78]. It is quite natural that the assertion of peace presupposes an appropriate level of civic self-awareness and social responsibility. Society cannot be imagined as the ideal construction of ideal individuals. All experiments on the artificial improvement of the nature of man and methods of social order, both speculative (various utopias), and real (eugenics, socialism) were not viable. Society is always a diversity of individual worlds, a complex construct of many specific communications [Bazaluk, 2015; Klepko, 2017]. As music is capable of implementing 'established harmony', and society aspires to find and maintain a balance of opposites and contradictions. The world is a harmony of a variety, and not unification and typology.

The appropriate explanation of this principle was given by Kerry Bickmore and other authors, "Peacebuilding refers to comprehensive social change, toward social-political equity 
and cultural inclusion, repairing direct and indirect root causes of destructive conflict by (re)creating sustainable inclusive processes for ongoing constructive nonviolent conflict" [Bickmore et al., 2017: 283]. Or in other words, "Agency for peacebuilding citizenship includes both capacities - knowledge and competencies for transforming conflicts and altering structures to affirm justice - and motivations - hope, commitment, and moral judgment to make difficult choices. Peacebuilding education thus includes citizenship education" [Bickmore et al., 2017: 283]. Therefore, there is a certain link between music and the specifics of self-realization of a person in the social and political aspect.

Speaking about the social and political realm of human existence in the context of peace education, it is impossible to avoid the concept of tolerance as a manifestation of harmony. We believe that music is an important factor in the spread of tolerance in the perception of oneself and the Other, the frankness in recognizing emotions and events, expanding the boundaries of perception and potential experience. After all, the conflict cannot be ignored, or localized eternally/forever. As the rhythm of the melody leads logically to the culmination, in the same way the conflict that has already arisen needs to be solved as well: "Developing capacity to acknowledge and handle conflicts as conflicts - as embodying competing perspectives or needs, the need for choice rather than mere absorption of 'truth' - is perhaps the foundation of democratic peacebuilding citizenship" [Bickmore et al., 2017: 300]. Music contains intentions of reconciliation. Therefore, it is important not to avoid the conflict at any price, but stereoscopic view, or polyphony of perception and reflection of strategic choice.

Besides, music allows to carry out a discourse of such subjects and problems which are critical for the engaged perception. So, the urgent problem of post-colonialism is a subject of numerous researches and disputes. But the solution of this problem is still very far. It is also emphasized by Michalinos Zembylas:"Understanding the historical effects of coloniality could be the first step to interrupt the reproduction of postcolonial peace understandings that naively assume social imaginaries of absolute peace or a pre-colonial purity" [Zembylas, 2017: 13]. That is, the phenomenon of colonialism is thoroughly rooted in the modern civilization. But music 'conquers' without resistance, engages in a particular cultural context and adapts a person to certain living conditions. And considering the general tendency of globalization, the definition of modern civilization as a cult of consumption and material values, the peace education gains special sharpness. Resources are exhaustive, the population of the planet and its devastating impact on the environment lead to the emergence of anti-utopias in relation to the future of the mankind. Therefore, one should agree with the following thesis: "Education, then, has generally failed to bring about social justice at a local and global level. It mainly serves the needs of dominant groups in society, and it has largely failed to bring about participatory democracy and critical consciousness. Regimes of testing and accountability have resulted in an impoverished view of what it is to know and be able to do, and have foregrounded the content of the curriculum at the expense of processes of learning. Education suffers crises of legitimation and representation grounded in structural and cultural violence" [Cremin, 2016: 5]. Music, firstly, is self-sufficient, and, secondly, it is capable to reorient a person from the measurement of material values to the values of eternal and spiritual. Harmony of music correlates with harmony of the world, integrity does not mean monotony, and stability does not presuppose the static character.

These fundamental moments of understanding in the peace education should be the starting point for the organization of the educational process: "If peace education aims to 
create unity, harmony and wholeness, then it undermines the legitimacy of the ground on which it stands if it compartmentalizes knowledge into fields and disciplines, and students into groupings based on age, ability, social class or religious belief (directly or indirectly)" [Cremin, 2016: 7]. As it was stated above, music is the most successful mediator for nonconflict communication and organic interactions. Thus, Elaine Sandoval pays close attention to the potential role of music in peace education, the problem of structural and indirect violence, which is quite common in the training programs in Europe as a center for education and technology, is carefully investigated in particular. [Sandoval, 2016]. Olivier Urbain, another well-known theorist of the concept of peace education, explores the synthesis of the transcendental methodology for transformation of conflicts and philosophy of peace that helps in research of the relationship between music and the teaching of peace, namely the unity of four values: the inner realization of peace, communicative creativity, planetary awareness and preventive peace building [Urbain, 2016].

Not smaller interest for justification of peacebuilding strategies through the arts education is represented by the universalist concept of Michael Golden, which justifies the idea of environmental friendliness and efficiency of human thinking as the fundamental factors of essence of human being, which is reflected in the course of social and cultural life [Golden, 2016]. However, the current challenges and goals of peace education need practical implementation in compliance with ecological and economic aspects in daily practice and in the general human contexts. That's why, the author proposes models for implementing this ambitious goal through musical exercises. Therefore, music as a tool for harmonizing individuals and societies attracts attention of researchers and practitioners of peace education quite rightly.

\section{Conclusions}

Music as the theoretical concept of ontology embodies the potentiality of harmonization in the existential experience of the main metaphysical categories of time and eternity, unique and general, form and content. Updating of long-term present, articulated in music, allows a person to find the necessary balance and focus of reflexive activity, which is necessary for the efficient organization of daily practices.

Music as an important factor in the psychological component of human nature carries out the harmonization of the emotional sensory component of the human soul through catharsis. Interaction with musical works contributes to expanding the limits of perception, tolerance and empathy as a way of understanding. These factors are important in the development of a person's emotional intelligence and stabilization of social life. In addition, music as the translator of the eternal values and ideals, produces in the human minds another system of assessments, different from the material and consumer way of life. Consequently, the attraction of the phenomenon of music to peace education is productive in the personal and social, political and global context as well.

\section{References}

Bahtizina, Dilybyar. Music in harmony of the world. Ufa, 2012 (in Russian).

Bazaluk, Oleg. Postmodernism: Philosophy of Education. Future Human Image. 5 (2), 2015: 9-22.

Bazaluk, Oleg. The Philosophy of Cosmos: the Place of Human at the Scale of Earth and Cosmos. Chapter One. Philosophy and Cosmology 16, 2016: 28-42. 
Bazaluk, Oleg and Denys Svyrydenko. Philosophy of War and Peace: In Search of New European Security Strategy. Anthropological Measurements of Philosophical Research. 12, 2017: 89-99.

Behr, Hella, Megoran, Nick and Jane Carnaffan. Peace education, militarism and neoliberalism: conceptual reflections with empirical findings from the UK. Journal of Peace Education. 15(1), 2018: 76-96. http://dx.doi.org/10.1080/17400201.2017.139 4283

Bickmore, Kerry, Salehin, Kaderi Ahmed and Ameri Guerra-Sua. Creating Capacities For Peacebuilding Citizenship: History and Social Studies Curricula in Bangladesh, Canada, Colombia, and México. Journal of Peace Education. 14(3), 2017: 282-309. http://dx.doi.org/10.1080/17400201.2017.1365698

Cremin, Hilary. Peace education research in the twenty-first century: three concepts facing crisis or opportunity? Journal of Peace Education, 13(1), 2016: 1-17. http://dx.doi.or $\mathrm{g} / 10.1080 / 17400201.2015 .1069736$

Golden, Michael. Musicking as education for social and ecological peace: a new synthesis. Journal of Peace Education. 13(3), 2016: 266-282. https://doi.org/10.1080/1740020 1.2016.1234612

Klepko, Serhiy. Pedagogy of Peace and Philosophy of War: the Search for Truth. Future Human Image. Volume 7, 2017: 46-49.

Kyvliuk, Olga, Polishchuk, Oleksandr, Svyrydenko, Denys and Olena Yatsenko. Educational Management as Education Diplomacy: Strategies for Ukraine. Naukovyi Visnyk Natsionalnoho Hirnychoho Universytetu. 3, 2018: 139-144. http://dx.doi. org/10.29202/nvngu/2018-3/23

Kostetzkiy, Yuriy. Philosophy of Music in the Space of the Theory of Education. Credo New. 1, 2013: 22-36.

Lewsader, Jeff and Judit Myers-Walls. Developmentally Appropriate Peace Education Curricula. Journal of Peace Education. 14(1), 2017: 34-51. http://dx.doi.org/10.1080 /17400201.2016.1228527

Rasheed, Rateeba and Alvaro Munoz. Higher education and peacebuilding - a bridge between communities? Journal of Peace Education. 13(2), 2016: 172-185. http:// dx.doi.org/10.1080/17400201.2016.1205003

Sandoval, Elaine. Potential contributions of music education to peacebuilding: curricular concerns. Journal of Peace Education. 13(3), 2016: 238-251. https://doi.org/10.1080 /17400201.2016.1234647

Svyrydenko, Denys. Divided Universities: The Postcolonial Experience of Contemporary Ukrainian Higher Education. Future Human Image. 7, 2017: 128-134.

Urbain, Olivier. A statement of values for our research on music in peacebuilding: a synthesis of Galtung and Ikeda's peace theories. Journal of Peace Education. 13(3), 2016: 218 237. https://doi.org/10.1080/17400201.2016.1256942

Yatsenko, Olena. Antique principle of paideia at challenges of contemporary society and culture. Educational discourse: collection of scientific papers. 2, 2017: 79-89 (in Ukrainian).

Zembylas, Michalinos: Con-/divergences between postcolonial and critical peace education: towards pedagogies of decolonization in peace education. Journal of Peace Education. 15(1), 2018: 233-247. http://dx.doi.org/10.1080/17400201.2017.1412299 